\title{
FISH-TAMB, a fixation-free mRNA fluorescent labeling technique, to target transcriptionally active members in microbial community
}

\section{Rachel L Harris}

Princeton University

Maggie C.Y. Lau Vetter ( $\sim$ maglau@idsse.ac.cn )

Institute of Deep-sea Science and Engineering (CAS) https://orcid.org/0000-0003-2812-9749

\section{Esta van Heerdeen}

North West University

\section{Errol Cason}

University of the Free State

Jan-G Vermeulen

University of the Free State

Anjali Taneja

Princeton University

Thomas L. Kieft

New Mexico Institute of Mining and Technology

Christina J. DeCoste

Princeton University

Gary Laevsky

Princeton University

Tullis Onstott

Princeton University

\section{Research Article}

Keywords: molecular beacons, cell-penetrating peptides, FISH, mRNA, methanogens, ANMEs

Posted Date: June 16th, 2021

DOI: https://doi.org/10.21203/rs.3.rs-179810/v1

License: (1) (1) This work is licensed under a Creative Commons Attribution 4.0 International License.

Read Full License 
Version of Record: A version of this preprint was published at Microbial Ecology on August 18th, 2021. See the published version at https://doi.org/10.1007/s00248-021-01809-5. 


\section{Abstract}

Keystone species or ecological engineers are vital to the health of an ecosystem, however, often their low abundance or biomass present challenges for their discovery, identification, visualization and selection. We report the development of fluorescent in situ hybridization of transcript-annealing molecular beacons (FISH-TAMB), a fixation-free protocol that is applicable to archaea and bacteria. The FISH-TAMB method differs from existing FISH methods by the absence of fixatives or surfactants in buffers, and the fast hybridization time of as short as 15 minutes at target cells' growth temperature. Polyarginine cellpenetrating peptides are employed to deliver molecular beacons (MBs) across prokaryotic cell walls and membranes, fluorescently labeling cells when MBs hybridize to target mRNA sequences. Here, the detailed protocol of the preparation and application of FISH-TAMB is presented. To demonstrate FISHTAMB's ability to label intracellular mRNA targets, differentiate transcriptional states, detect active and rare taxa, and keep cell viability, labeling experiments were performed that targeted the messenger RNA (mRNA) of methyl-coenzyme $\mathrm{M}$ reductase $\mathrm{A}(\mathrm{mcr} \mathrm{A}$ ) expressed in 1$)$ Escherichia coli containing a plasmid with a partial mcr A gene of the methanogen Methanosarcina barkeri (E. coli $m c r A+) ; 2) M$. barkeri ; and 3) an anaerobic methanotrophic (ANME) enrichment from a deep continental borehole. Although FISH-TAMB was initially envisioned for mRNA of any functional gene of interest without a requirement of prior knowledge of 16S ribosomal RNA (rRNA)-based taxonomy, FISH-TAMB has the potential for multiplexing and going beyond mRNA, thus is a versatile addition to the molecular ecologist's toolkit, with potentially widespread application in the field of environmental microbiology.

\section{Introduction}

Microbial keystone species have been proposed based mostly on network analysis, and only a few of them are associated with experimental evidence [1]. Although the various definitions of "keystone species" have not been unified, some taxa have been recognized to be playing a pivotal role in shaping the structure and dynamics of their ecosystems despite their small population sizes at a particular point in time or space $[1,2]$. The study of the deep biosphere, where primary productivity is basically fueled by geo-gases and inorganics, has been focused on the aspects of biosafety [3], evolution and adaptation under extreme conditions [4], and astrobiology [5]. As the knowledge of the deep biosphere begins to unfold, such as the underexplored rare biosphere [6], the uncharted biodiversity [7], it is believed that rare, uncultured taxa could be the keystone species or ecological engineers in the deep biosphere [8]. The first step towards identifying a rare, uncultured taxon being a key or keystone species in the deep biosphere and other ecosystems is to demonstrate that the low-abundance population is metabolically active, then to characterize their genomes and physiologies, and subsequently to evaluate or perhaps even quantify their ecological importance.

To pull out information about metabolically active, low-abundance populations from the rest of the microbial community, several methods can be used. Shotgun sequencing of total RNA from environmental samples, metatranscriptomics, reveals the in situ metabolic active members in the bulk samples [8]. Bioinformatics analyses aid the identification of functional genes expressed by active 
members, providing a context to infer how rare microorganisms may interact with the rest of the community. However, the information originating from these rare members may each only account for less than $1 \%$ of the data, and it often begs for more sequencing to be performed to address the low coverage. Metatranscriptomics of total RNA is therefore not a cost-effective way for studying ecologically important members that occur at a low abundance in environmental samples. Also, analyzing and recruiting RNA information of rare taxa from metatranscriptomics datasets are deemed to be challenging in terms of bioinformatics.

Traditional fluorescence in situ hybridization (FISH) using linear probes that target the $16 \mathrm{~S}$ ribosomal RNA (rRNA) [9] and/or messenger RNA (mRNA) [10] allow transcriptionally active cells to be visualized by microscopy. The probes inform some level of information about the taxonomic group and function of the fluorescence-labeled cells depending on the universality of the designed probe. The challenge to visualize cells with low transcript content can be alleviated by replacing linear probes with molecular beacons that have low background signal [11], and by the use of catalyze reporter deposition (CARD) [12] or hybridization chain reaction (HCR) [13] that amplifies the fluorescence signal from the target molecules. These modified FISH methods increase the target-to-background signal ratio. Combining FISH with flow cytometry and chip-based microarray meets the need for high throughput detection and quantification, whereas combining FISH with cell-sorting allows cell enrichment and separation for subsequent cultureindependent work [14]. Similarly, translationally active cells from environmental samples can also be studied by employing bioorthogonal noncanonical amino acid tagging (BONCAT) methodology [15]. These labelling approaches, however, typically involve a fixation step that crosslinks proteins and nucleic acids [16], thereby inactivating the microbial cells, rendering impossible the capture of labeled rare taxa for live-cell imaging experiments and cultivation-based research.

Fixation-free 16S rRNA FISH has been applied on environmental samples and demonstrated that the twostage sort approach enriched the target populations from 2-3\% to $94-98 \%$ [17], but cultivation of labeled cells was not attempted. This in-solution fixation-free protocol involves an incubation of cells in a hybridization buffer containing $0.01 \%$ SDS and $0.9 \mathrm{M} \mathrm{NaCl}[17,18]$ at $46^{\circ} \mathrm{C}$ for $2-3$ hours, followed by an incubation in a wash buffer $(0.9 \mathrm{M} \mathrm{NaCl})$ at $48^{\circ} \mathrm{C}$ for $20 \mathrm{~min}$. The hybridization conditions, in particular the elevated temperature (presumably higher than the native temperature of the bioreactor samples, which was not stated in Ref. 18 or references therein), may stress the target cells and reduce their viability. It has not yet been tested whether this fixation-free protocol alters the physiology and viability of the target cells or not. Fixation-free protocols that employed ethanol dehydration [19] and heat shock [20] would lower the survivability of the cells, as the latter study targeting the 16S rRNA gene reported less than $3 \%$ survival rate of pure cultures. Therefore, a FISH sample preparation protocol that works under conditions similar to the native conditions of target cells will be advantageous for in situ monitoring of cellular activity, and for investigating the physiology of uncultured, non-model organisms in a mixed community, which has the potential to meet the growing need to enrich, isolate and characterize the physiology of uncultured species. 
In this article, we describe the development of fluorescent in situ hybridization of transcript-annealing molecular beacons (FISH-TAMB) to label intracellular mRNA targets in prokaryotic cells. The FISH-TAMB method differs from existing FISH methodologies by the absence of fixatives or surfactants in buffers, and a fast hybridization time of as short as 15 mins at target cells' growth temperature. The initial development of the FISH-TAMB method targets the marker gene of methanogens and the uncultivated anaerobic methanotrophic archaea (ANMEs) [21], which are known to account for $~ 1-2 \%$ of read abundance in several continental subsurface microbial communities [22] and are evident to take part in the subsurface methane cycle $[8,23]$. Labeling of intracellular mcrA transcripts, encoding for the alpha subunit of methyl-coenzyme $M$ reductase that mediates, respectively, the last and first step of methanogenesis and anaerobic methanotrophy, was demonstrated in cells from three scenarios: (i) Escherichia coli cells carrying a plasmid with an insert of partial mcrA gene derived from Methanosarcina barkeri (E. coli $\mathrm{mcrA}^{+}$), (ii) an M. barkeri axenic culture, and (iii) ANMEs enriched from Precambrian shield subsurface fracture fluid (BE326 BH2-Conc) $[8,23]$. Viability of FISH-TAMB-treated E. coli $\mathrm{mcrA}^{+}$and $M$. barkeri cells was evaluated.

\section{Materials And Methods}

\section{Concept of FISH-TAMB}

Molecular beacons (MBs), with a hairpin oligonucleotide sequence outfitted with a fluorophore and a fluorescence quencher [24] were selected to target the mRNA of bacteria and archaea, as they result in a higher signal-to-background noise ratio than linear probes and have also been successfully applied to detect intracellular mRNA of living eukaryotic cells $[11,25,26]$. In the unbound state, complementary bases on the $5^{\prime}$ and $3^{\prime}$ ends of MBs self-anneal to form a stem structure, which results in fluorescence quenching. Recognition of a target sequence results in MB linearization for subsequent hybridization (Fig. 1). Thus, the fluorophore is no longer in physical proximity to the quencher, resulting in emission of a known wavelength at a level differentiable from the background fluorescence due to autofluorescence and unbound MBs.

In order to deliver the MBs into prokaryotic cells without causing cell death, cell-penetrating peptides (CPP) are used, as they have been shown to successfully deliver cargos such as DNA and nanoparticles into living cyanobacteria with negligible toxicity $[27,28]$. Following the formation of FISH-TAMB probes (i.e. CPP/MB complexes) via non-covalent hybridization of MBs to CPP, FISH-TAMB probes are incubated with microbial cells in a mineral salt solution at the cells' growth temperature. The MBs are believed to be taken up by prokaryotic cells via classical endocytosis and/or micropinocytosis [29], though it is uncertain how broadly applicable these mechanisms may be. Little is known about trafficking of the internalized FISH-TAMB probes within the cells. It is anticipated that the MBs will be dissociated from $\mathrm{CPP}$ due to some enzymatic reaction, then the released MBs encountering RNA molecules with a sequence complementary to the MB sequence will result in hybridization and fluorescence emission. 
Cells labeled by the FISH-TAMB method can be visualized under epifluorescence and confocal microscopy, enumerated and sorted with flow cytometry and microfluidics, and collected for cultureindependent and culture-dependent investigations.

\section{Step 1: Molecular Beacon (MB) Design and Acquisition}

MB sequences can be designed for a spectrum of specificity/universality: as a specific probe targeting one single taxon, as a universal probe that potentially hybridizes to all RNA variants of the target functional gene, or anywhere in between. In this study, two type of MBs were used and each comprised a GC-rich stem and 24-mer nucleotide probe sequence. The lacZa MB sequence (5'-

CCTGGCACTAGTGATATCGAATTCCCGCGCCAGG-3'; Integrated DNA Technologies, Inc., Coralville, IA, USA) was designed to target the region of lacZa gene on the $\mathrm{PGEM}^{\circledR}$-T Easy Vector where the insertion site is located, such that disruption of this annealing site due to gene insertion will result in no FISH-TAMB hybridization with the expressed mRNA. The mcrA MB sequence (5'-

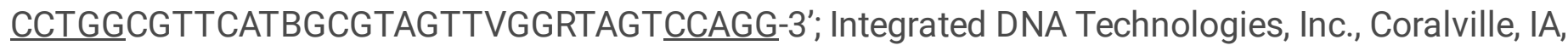
USA) was modified from the reverse primer that has been commonly used in diversity studies of methanogens and ANMEs belonging to phylum Euryarchaeota [30], anticipating to capture diverse cells expressing different mcrA genes. The underline regions are predicted to form the stem portion. Both MBs have a similar melting temperature and GC content. MBs are flanked on the 5' end by a covalently bound Cy3 (excitation peak at $554 \mathrm{~nm}$, and emission peak at $566 \mathrm{~nm}$ ) or Cy5 fluorophore (excitation peak at $649 \mathrm{~nm}$, and emission peak at $665 \mathrm{~nm}$ ) and on the 3' end by a Black Hole Quencher ${ }^{\circledR}$ BHQ3. MBs, purified by high-pressure liquid chromatography, were ordered from Millipore Sigma, St. Louis, MO, USA.

As the additional bases for the stem structure may affect the desired specificity of the MB to target mRNA, a BLAST (https://blast.ncbi.nlm.nih.gov/Blast.cgi) search against the nucleotide database was done to confirm that the MB sequences remained highly similar to sequences of the target taxa. As the lacZa MB sequence exactly targets a vector sequence and the mcrA MB sequence is derived from a wellknown primer sequence, non-specific hybridization was not a concern in this study. For a newly designed probe targeting a non-laboratory-use-vector, a more vigorous evaluation of its specificity is recommended (e.g. [31]).

To minimize photodegradation, all laboratory work involving MBs was done in dim light. Solutions containing MBs and FISH-TAMB probes were kept in the dark unless otherwise specified.

\section{Step 2: MB Validation (optional but recommended)}

For one who is setting up the laboratory for performing FISH-TAMB or is going to use newly designed FISH-TAMB probes, it would be a good practice to obtain empirical data about the MBs. Conducting a thorough study to characterize the thermodynamic and kinetic properties [32] of the MBs is deemed unnecessary for every application; nonetheless, it is advantageous for the user to at least find out how easily the GC stem structure may open in the absence of the target molecules, and given the detection systems available, the fluorescence levels of the unbound and bound states. 
We performed two cell-free or in vitro hybridization assays on the mcrA MBs with a Cy3 fluorophore. Melting curve analysis was done to examine the temperature and salt effects on the integrity of the mcrA $\mathrm{MBs}$ in the presence and absence of its target sequence. Reactions of $50 \mathrm{~mL}$ containing $20 \mathrm{pmol}$ of $\mathrm{mcr}$ $\mathrm{MB}$ and 40 pmol of perfect-match target oligonucleotide (5'-ACTAYCCBAACTACGCVATGAACG-3';

Integrated DNA Technologies, Inc., Coralville, IA, USA) were prepared in sterile water, and a $20 \mathrm{mM}$ Tris- $\mathrm{HCl}$ buffer solution containing $1,2.5$ and $5 \mathrm{mM} \mathrm{MgCl}_{2}$. A set of no-template controls containing no target oligonucleotides was included. Reaction mixtures were incubated at $37^{\circ} \mathrm{C}$ for an hour on a real-time qPCR 7900HT system (Applied Biosystems, Inc., Carlsbad, CA USA), followed by melting curve analysis for temperatures going from $95^{\circ} \mathrm{C}$ to $25^{\circ} \mathrm{C}$ with fluorescence signals measured every $0.2^{\circ} \mathrm{C}$ at $570 \mathrm{~nm}$ (pre-set for NED dye). The thermal profile and data acquisition was set up using software SDS v2.3. The results (Fig. S1; Table S2) showed that the hybridization of mcrA MBs and target oligonucleotides (i.e. bound state) at below $65^{\circ} \mathrm{C}$ and in the presence of $\mathrm{MgCl}_{2}$ resulted in about 27- to 193-folds of increase in fluorescence intensity than the unbound state; salt is essential for keeping the stem structure, but the formation of MB-target complexes at higher concentration of salt $\left(5 \mathrm{mM} \mathrm{MgCl}_{2}\right)$ resulted in a lower fluorescence intensity when compared to that at lower salt concentrations, suggesting that a higher salt concentration may have increased the activation energy required for the linearization of MBs; complete dissociation of MB-target complexes occurred at $\sim 65^{\circ} \mathrm{C}$ and MBs were denatured to a random coil state at higher temperatures, suggesting that mcrA MBs may be limited from in situ studies of thermophilic methanogens and ANMEs.

A similar experiment was done using $2 \mathrm{pmol}$ of $\mathrm{mcr}$ MBs and $4 \mathrm{pmol}$ of target oligonucleotides, that is 10 times less than the abovementioned experiment. The fluorescence intensities of the bound state and unbound states were low, and their differences were relatively small (at most 5-folds), suggesting that this degree of change was approaching to the real-time qPCR 7900HT system's empirical detection limit for differentiating bound and unbound MBs with a Cy3 fluorophore.

As one of the later experiments would apply FISH-TAMB for a long period of observation (>240 min), a time-series experiment was set up to investigate the fluorescence stability of mcrA MBs with a Cy5 fluorophore. Reactions of $100 \mathrm{~mL}$ containing $40 \mathrm{pmol}$ of $m c r \mathrm{AB}$, with or without $40 \mathrm{pmol} m c r A$ target oligonucleotide, were prepared in $1 \mathrm{X}$ Dulbecco's PBS (DPBS) solution. After incubation at room temperature for $10,15,20,30,40,60,80$ and 100 min, the reaction mixtures were transferred to a Corning ${ }^{\text {TM }}$ 96-well special optics low fluorescence assay plates (Thermo Fisher Scientific, Waltham,

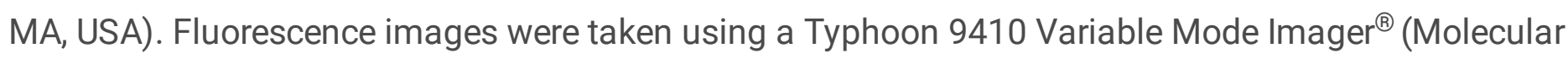
Dynamics, GE Healthcare, Little Chalfront, UK) with excitation at $633 \mathrm{~nm}$, detection at 670/10 nm, and an exposure time of $5 \mathrm{~min}$ per image. The results (Fig. S2) showed that the fluorescence intensities of MBtarget complexes and unbound MB remained constant over the tested duration. As shown, validation experiments can be designed with conditions that are relevant to the downstream analyses, and a variety of instruments can be used for fluorescence detection.

\section{Step 3: Formation of FISH-TAMB Probes}


CPP nine arginine residues (R9) was selected as a carrier to deliver MBs across cell walls and plasma membranes, as it has been demonstrated to penetrate cyanobacterial walls and membranes without harmful effects $[27,28]$. FISH-TAMB probes were formed by mixing R9 and MB molecules together at an optimized ratio, which can be determined by gel retardation assay.

We used a protocol modified from Liu et al. [28]. Briefly, R9 and MB stock and working solutions were prepared in 1 X TE buffer ( $10 \mathrm{mM}$ Tris-HCl, $1 \mathrm{mM}$ EDTA-Na ${ }_{2}, \mathrm{pH} \mathrm{8.0)}$. Aliquots of $200 \mathrm{mM} \mathrm{R9}$ and $10 \mathrm{mM}$ MB were mixed gently in $1^{\prime}$ DPBS solution at varying molar nitrogen/phosphate ratios ( $\mathrm{N}$ from $\mathrm{R} 9$, and $\mathrm{P}$ from MB) $(0: 1,5: 1,10: 1,15: 1,20: 1,25: 1,30: 1)$. The mixtures were incubated for $30 \mathrm{~min}$ at $37^{\circ} \mathrm{C}$ on a C1000 Touch"' Thermal Cycler (Bio-Rad Laboratories, Inc., Irvine, CA USA) to allow for the complexation of all free-floating MBs in solution. Afterward, the mixtures were mixed with 1X DNA loading dye (Thermo Fisher Scientific, Waltham, MA USA), and analyzed by electrophoresis on a $1 \%(\mathrm{w} / \mathrm{v})$ agarose gel containing ethidium bromide in 1X TAE buffer solution (40 mM Tris, pH 7.6; $20 \mathrm{mM}$ acetic acid, $1 \mathrm{mM}$ EDTA-Na ${ }_{2}$ ) for 30 min at 100 V. A 100 bp ladder (New England BioLabs ${ }^{\circledR}$, Ipswich, MA USA) was used as a size-marker.

For the probes used in this study, a R9 to MB molar ratio of 20:1 was found to be adequate for R9s to scavenge all free MBs in the solution (Fig. S3). Therefore, the FISH-TAMB probe working solution used in this study was prepared at a 20:1 R9:MB molar ratio (i.e. containing $20 \mathrm{mM} \mathrm{R9}$ and $1 \mathrm{mM} \mathrm{MB}$ ) using the protocol mentioned above, and stored in the dark at $-20^{\circ} \mathrm{C}$ until use.

\section{Step 4: Validation of the delivery of FISH-TAMB Probes and subsequent hybridization with target transcripts (optional but recommended)}

Before conducting a full experiment to answer the scientific questions of interest, it is advantageous to do a procedural check to verify that the prepared FISH-TAMB probes can pass the cell membrane barrier and enter into the cytoplasm, that the internalized MBs can bind to the target molecule if present, and that the resultant fluorescence level can be confidently differentiable from the background signal. As FISH-TAMB

probes are intended to be used to label intracellular mRNA under conditions similar to that of the sample's native conditions (e.g. temperature, salinity or osmolarity, $\mathrm{pH}$, etc.), it is recommended to do this in vivo validation step with conditions consistent with the future experiments.

As a proof of concept, our FISH-TAMB probes appended with Cy5 fluorophore were applied to label mRNA expressed by bacterial and archaeal cells, represented by pure cultures of $E$. coli and $M$. barkeri, as well as an ANME enrichment. The construction of $E$. coli cells with a plasmid containing a partial $p m o A$ (particulate methane monooxygenase beta subunit) (pGEM-T::pmoA) or $m c r A$ gene (pGEM-T::mcrA) and the cultivation conditions of all types of cells are detailed in the Supplementary Methods. These E. coli cells will be referred as E. coli $\mathrm{pmoA}^{+}$and $E$. coli $\mathrm{mcrA}^{+}$. In this study, considering that the FISH-TAMBlabeled samples were analyzed by flow cytometry, it was required to suspend the cells in $1^{\prime}$ DPBS solution to reduce background particle counts. 
Cells were harvested during their exponential phase with cell concentration determined via optical density at $600 \mathrm{~nm}\left(\mathrm{OD}_{600}\right)$ for $E$. coli using a Beckman $\mathrm{DU}^{\circledR} 530$ Life Science UV/Vis Spectrophotometer (Beckman Coulter $^{\circledR}$, Indianapolis, IN USA), and at $550 \mathrm{~nm}\left(\mathrm{OD}_{550}\right)$ for M. barkeri [33] and ANMEs using a Hach DR/2010 Spectrophotometer (Hach Company, Loveland, CO, USA). An appropriate volume of cells, usually less than $1 \mathrm{~mL}$, was added to $100 \mathrm{~mL}$ of $1 \mathrm{mM}$ mcrA FISH-TAMB probe working solution (equivalent to $100 \mathrm{pmol} \mathrm{MBs}$ ), to dilute the cells to $\sim 10^{6}$ cells $/ \mathrm{mL}$. Cell-free reactions of $100 \mathrm{~mL}$ volume were set up as follows: A) MB-only control: 1' DPBS containing 40 pmol mcrA MBs; B) MB+non-specifictarget control: 1' DPBS containing 40 pmol mcrA MBs and 40 pmol pmoA oligonucleotide (5'GAAYSCNGARAAGAACGM-3'; Integrated DNA Technologies, Inc., Coralville, IA, USA) modified from Luesken et al. [34]; C) MB+specific-target control: 1' DPBS containing 40 pmol mcrA MBs and 40 pmol mcrA oligonucleotide; D) FISH-TAMB-only control: 1' DPBS containing 100 pmol mcrA MBs in the form of FISH-TAMB probe; and E) FISH-TAMB+specific-target control: 1' DPBS containing 100 pmol mcrA MBs in the form of FISH-TAMB probe and 100 pmol mcrA oligonucleotide. After incubation on a thermal cycler at $37^{\circ} \mathrm{C}$ for $30 \mathrm{~min}$, the reaction mixtures were transferred to a Corning ${ }^{\mathrm{TM}}$ 96-well special optics low fluorescence assay plates (Thermo Fisher Scientific, Waltham, MA, USA). Fluorescence images were taken using a Typhoon 9410 Variable Mode Imager ${ }^{\circledR}$ (Molecular Dynamics, GE Healthcare, Little Chalfront, UK) with excitation at $633 \mathrm{~nm}$, detection at $670 / 10 \mathrm{~nm}$, and exposure time of $5 \mathrm{~min}$. The results showed that the fluorescence of unbound mcrA MBs in the absence of specific targets (Fig. S4A and S4B) was clearly lower than that of mcrA MB-mcrA targets (Fig. S4C); whereas the mcrA FISH-TAMB probes emitted undetectable fluorescence in the absence or presence of targets (Fig. S4D and S4E, respectively). In comparison, $M$. barkeri, the ANME enrichment and $E$. coli mcrA $^{+}$that are known and expected to express mcrA mRNA yielded fluorescence signals (Fig. S4F, S4G and S4H, respectively), indicating that the mcrA FISH-TAMB probes were successfully delivered into the cells. We hypothesized that after FISH-TAMB are internalized by the M. barkeri, the ANME enrichment, and E. coli crA $^{+}$cells, the MBs are liberated from the CPP (i.e. R9 in this study), and presumably hybridized to the specific target mRNA (i.e. mcrA in this study) inside the cells. In contrast, FISH-TAMB probes remain stable in cell-free conditions, wherein the CPPs remain non-covalently bound to MBs, keeping MBs from hybridizing to the specific target mRNA. While the exact mechanism remains unknown, the MBs released from R9s appear to retain hairpin conformation following cellular penetration, as evidenced by minimal fluorescence in the negative control $E$. coli $p m o A^{+}$cells incubated with FISH-TAMB probes (Fig. S4I). This procedural check provided the first remarkable sign that the mcrA FISH-TAMB probes labeled mcrA-expressing archaeal and bacterial populations.

\section{Step 5: Applications of FISH-TAMB Probes}

Here we describe three examples as a demonstration of FISH-TAMB labeling of cells that expressed the target mcrA mRNA, and its combined use with flow cytometry and fluorescence microscopy.

(1) Enumeration of FISH-TAMB labeled cells by flow cytometry 
This experiment was performed to illustrate that living cells are labeled by FISH-TAMB due to the expression of the target mRNA. E. coli cultures were used as the subject of study because of their easy manipulation and relatively fast doubling time. In principle, $E$. coli cells each carrying the transformed plasmid should express the gene insert upon induction of the lacZ operon where the insertion site is located. Thus, induced and uninduced $E$. coli $\mathrm{mcrA}^{+}$cells were subjected to mRNA detection by $\mathrm{mcr} A$ FISH-TAMB probes appended with a Cy5 fluorophore. E. coli $\mathrm{mcrA}^{+}$cell suspensions were split into two equal volumes when the $\mathrm{OD}_{600}$ reached $>0.6$. One of the halves was induced with Isopropyl $\beta$-D-1thiogalactopyranoside (IPTG) at a final concentration of $1 \mathrm{mM}$. The cell suspensions, with or without IPTG addition, were incubated for 4 hours more at $37^{\circ} \mathrm{C}$ with shaking at $150 \mathrm{rpm}$. Afterward, optical density was measured again and an appropriate volume (less than $1 \mathrm{~mL}$ ) of uninduced and induced cells was taken for dilution to $\sim 10^{6} \mathrm{cells} / \mathrm{mL}$ in $100 \mathrm{~mL}$ of $1 \mathrm{mM}$ mcrA FISH-TAMB probe working solution (equivalent to 100 pmol MBs in 1' DPBS). (It was found that 1' DPBS gave a significantly lower noise (event counts) in flow cytometry analysis than home-made PBS solution.) The reactions without FISHTAMB probes were used to set gates for cell populations.

In addition, non-specific target controls were included to reveal the number of cells labeled as a result of potentially non-specific hybridization: $1 \mathrm{mM}$ mcrA FISH-TAMB probes were applied to IPTG-induced $E$. coli lacZa ${ }^{+}$cells (i.e. pGEM-T::/acZa, without a mcrA gene insert), and $1 \mathrm{mM}$ lacZa FISH-TAMB probes were applied to IPTG-induced $E$. coli $\mathrm{mcrA}^{+}$cells (i.e. without an intact lacZa gene). IPTG induced cells were prepared as described above. For background subtraction, cell-free controls were set up to collect fluorescence signals from the unbound mcrA or lacZa FISH-TAMB probes in the buffer solution, which contains $1 \mathrm{mM}$ mcrA or lacZa FISH-TAMB probes in 1' DPBS, plus $1 \mathrm{~mL}$ Luria Broth containing 0.05 $\mathrm{mg} / \mathrm{mL}$ ampicillin (LB/A).

All reactions were prepared in triplicates. Following incubation at $37^{\circ} \mathrm{C}$ for $15 \mathrm{~min}$ on a thermal cycler, reaction mixtures were diluted in $0.9 \mathrm{~mL} 1^{\prime}$ DPBS solution containing Fluoresbrite ${ }^{\text {t" }}$ plain red $0.5 \mathrm{~mm}$ microspheres (Polysciences, Inc., Warrington, PA, USA) at the final concentration of $\sim 10^{5}$

microspheres $/ \mathrm{mL}$, approximating to the cell concentrations. Fluorescent microsphere counts were used to calculate the volume of fluids analyzed, which was then used to determine the actual cell concentrations. All reactions were kept on ice and in dark until analyzed to reduce cellular activity and photodegradation of fluorophores.

Flow cytometry was performed on a BD LSRII Multi-Laser Analyzer (BD Biosciences, San Jose, CA, USA) at the Princeton University Flow Cytometry Resource Facility. Data were acquired for 120 seconds for each sample at $8 \mathrm{~mL} / \mathrm{min}$ average flow rate using four independent laser channels at default wattage settings ( $355 \mathrm{~nm}$ at $30 \mathrm{~mW}, 405 \mathrm{~nm}$ at $50 \mathrm{~mW}, 488 \mathrm{~nm}$ at $20 \mathrm{~mW}$, and $640 \mathrm{~nm}$ at $40 \mathrm{~mW}$ ). Forward and side-scattered light were set to logarithmic scale and used to trigger events. The system was flushed with 10\% (v/v) bleach solution for 1 min followed by de-ionized water for 1 min before and after analysis, and between samples to minimize the potential for cross-contamination. 
Cell-sized objects (hereafter called "cells") were gated with respect to the side-scattered light area and fluorescence signals of microspheres along the 575/26 nm (PE) bandpass filter. This gate was sufficient to identify E. coli cells based on known autofluorescence properties [35]. FISH-TAMB-labeled cells were identified as appropriately autofluorescent cells that also demonstrated at least a $10 \%$ increase in fluorescence on a 670/30 nm (Cy5) bandpass filter relative to the non-FISH-TAMB-treated cell populations. Gating was performed using BD FACSDiva v8.0.1 software (BD Biosciences, San Jose, CA, USA). The number of events gated as "cells" and "FISH-TAMB-labeled cells" in the cell-containing samples were determined, from which were subtracted the number of corresponding events gated in the respective cell-free controls containing mcrA or lacZa FISH-TAMB probes. Statistical analysis of observed differences in FISH-TAMB labeling between pairs of samples was performed using Student's t-test in Microsoft Excel.

Flow cytometry results were supplemented by examination under confocal fluorescence microscopes, including an attempt for 3D imaging of FISH-TAMB labeled cells (Video S1). The description is provided in the next section and Supplementary Materials. Raw flow cytometry data and microscopy images are available upon request.

(2) Visualization of FISH-TAMB labeled cells by spinning-disk fluorescence confocal microscopy

This experiment was performed to illustrate that cells at different transcriptional states could be revealed by FISH-TAMB labeling. Changes in the growth environment trigger microbial response within individual cells and across the cell population. Cells at exponential phase, and when stressed are known to enter, broadly speaking, different metabolic states, or more specially, different transcriptional states. M. barkeri cells were used partly because they are a natural host of $m c r A$ gene, and partly because the strict anaerobe is easily stressed by exposure to $\mathrm{O}_{2}$ in the air.

M. barkeri cells were harvested at the exponential phase as determined by $\mathrm{OD}_{550}$ readings. An appropriate volume $(50 \mathrm{~mL})$ of $M$. barkeri cells was taken for dilution to $\sim 10^{6} \mathrm{cells} / \mathrm{mL}$ in $100 \mathrm{~mL}$ of $1 \mathrm{mM} \mathrm{mcrA}$ FISH-TAMB (Cy5) probe working solution (equivalent to 100 pmol MBs) prepared using degassed 1 'DPBS in an anaerobic glove bag (Coy Laboratory Products, Grass Lake, MI, USA) to maintain cell activity in the absence of atmospheric $\mathrm{O}_{2}$. After a 15 -min incubation at $37^{\circ} \mathrm{C}$, the reaction volume was gently mixed by pipetting and transferred in full into individual wells of an 8-well chambered cover glass (Cellvis, Mountain View, CA USA, cat. \# C8-1.5H-N) and subsequently fitted into a Okolab stage-top chamber (Okolab, Ottaviano, Italy). This chamber provides a humidity controlled environmental chamber at $25^{\circ} \mathrm{C}$ under a $100 \% \mathrm{CO}_{2}$ atmosphere during imaging, to keep anaerobicity and to minimize focus drift.

In addition, to assess the transcriptional state of $M$. barkeri under stress, $M$. barkeri cells were exposed to atmospheric $\mathrm{O}_{2}$ by transferring $1 \mathrm{~mL}$ aliquots ( $\sim 0^{8}$ cells) into sterile $1.5 \mathrm{~mL}$ eppendorf tubes and incubated under aerobic condition at $37^{\circ} \mathrm{C}$ overnight with shaking at $150 \mathrm{rpm}$. Exposure to $\mathrm{O}_{2}$ was verified via media color change from clear (anaerobic) to bright pink (oxidized) as indicated by $\mathrm{O}_{2}$ sensitive resazurin in solution. FISH-TAMB hybridization was performed as described above. 
FISH-TAMB-treated $M$. barkeri samples were imaged using an Olympus BX-60 microscope equipped with a MPlan 100X magnification/0.90 BD Infinity objective, a 3 M-Pixel Digital Camera (Olympus), and Osram HBO Mercury burner (103 watts) and tungsten-halogen lamp (100 watts). The DAPI (352-477 nm) and Texas Red (633-738 nm) filters were applied when observing F420 autofluorescence of $M$. barkeri and the Cy5 fluorescence of FISH-TAMB probes, respectively. Composite micrographs were generated from raw microscopy images using ImageJ v. 2.0.0-rc-69/1.52n. Images were enhanced to show contrast using Adobe Photoshop Elements 15 (Adobe Inc., San Jose, CA USA).

Microscopic observations of $M$. barkeri from the exponential phase and that grown in contact with air were supplemented by flow cytometry. Following incubation with FISH-TAMB probes, reaction mixtures were diluted in $0.9 \mathrm{~mL}$ degassed 1' DPBS solution containing Fluoresbrite ${ }^{\mathrm{Tm}}$ plain red $0.5 \mathrm{~mm}$ microspheres (Polysciences, Inc., Warrington, PA, USA) at a final concentration of $\sim 10^{5} \mathrm{microspheres} / \mathrm{mL}$, and then analyzed as described above.

\section{(3) FISH-TAMB labeling of active ANMEs in an enrichment culture}

This experiment was performed to illustrate that active, low-abundance populations are labeled by FISHTAMB method. Active anaerobic methane oxidation (AOM) at the borehole BE326 BH2, a deep continental biosphere habitat, was due to the activity of uncultured ANMEs [8, 23]. We obtained an AOM microbial consortia by supplement of ${ }^{13} \mathrm{CH}_{4}$ and sulfate to $\mathrm{BE} 326 \mathrm{BH}$-Conc fracture fluid, and from the consortia total DNA was extracted and analyzed for community composition. Metagenomic analysis was performed to confirm the presence of ANME-2 lineages and their relative abundance. The methodology for enrichment, DNA extraction and metagenomic analysis are detailed in the Supplementary Methods.

FISH-TAMB hybridization followed by spinning-disk confocal microscopy and flow cytometry were performed as described for M. barkeri cultures above. Briefly, after 50 days of incubation, cell concentration was determined by $\mathrm{OD}_{550}$ measurements, and cells were harvested. An appropriate volume $(50 \mathrm{~mL})$ of cells was taken for dilution to $\sim 10^{6}$ cells $/ \mathrm{mL}$ in $100 \mathrm{~mL}$ of $1 \mathrm{mM}$ mcrA FISH-TAMB (Cy5) probe working solution (equivalent to $100 \mathrm{pmol} \mathrm{MBs}$ ) prepared using degassed 1' DPBS in an anaerobic glove bag to maintain cell activity in the absence of atmospheric $\mathrm{O}_{2}$. After incubation at $37^{\circ} \mathrm{C}$ for $15 \mathrm{~min}$ on a thermal cycler, reaction mixtures were transferred to individual wells of a Cellvis chambered cover glass and imaged as described above for M. barkeri. Instead of taking still images, live-cell time-lapse imaging data was acquired every min for 14.5 hours, with multiple positions recorded simultaneously using an MS-2000 motorized stage (Applied Scientific Instrumentation, Eugene, OR, USA). It is specially noted that the Perfect Focus System (PFS) on the Nikon Ti-E is a unique hardware solution designed to combat axial focus fluctuations in real time during long-term imaging investigations, which monitors and maintains the distance between the objective and the specimen, and has a response time in milliseconds.

To constrain the taxonomic identity of the FISH-TAMB-labeled cells in this AOM consortia, the 16S rRNA FISH probe EelMS-932 (5'-AGCTCCACCCGTTGTAGT-3') targeting the ANME-2 subpopulation [36, 37] was used. A set of FISH-TAMB-treated cells were prepared from the AOM enrichment as mentioned earlier, and 
were then fixed following an established FISH protocol [38]. Briefly, the FISH-TAMB-treated cells were centrifuged at 2,000 g for $5 \mathrm{~min}$ and washed once in 1' DPBS. The supernatant was pipetted off and cells were resuspended in a 1:1 mixture of chilled absolute ethanol and $1^{\prime}$ DPBS, and stored overnight at $-20^{\circ} \mathrm{C}$ before subsequent filtration onto a $0.2-\mathrm{mm}$ polycarbonate membrane filter (Whatman International Ltd., Maidstone, UK). Filters were washed twice with filter-sterilized distilled MilliQ water and then once with chilled absolute ethanol, then allowed to air-dry before being stored at $-20^{\circ} \mathrm{C}$ until $16 \mathrm{~S}$ rRNA FISH treatment.

For traditional 16S rRNA FISH method, filter sections (containing fixed cells) were cut with flame-sterilized razor blades and placed on glass slides. Hybridization of fixed cells were performed using $50 \mathrm{ng} / \mathrm{mL}$ of dual-labeled EelMS-932, with an Atto 565 fluorophore at both the 5'- and 3'-end for stronger fluorescence signal (Biomers.net, Ulmer, Germany; ATTO-TEC GmbH, Siegen, Germany) in $2 \mathrm{~mL}$ hybridization buffer containing $900 \mathrm{mM} \mathrm{NaCl}, 20 \mathrm{mM}$ Tris- $\mathrm{HCl}$ at pH 7.4, and 0.01\% w/v SDS. Formamide was added to a final concentration of $40 \%(\mathrm{v} / \mathrm{v})$ according to previously established hybridization stringency assessments [36]. 16S rRNA FISH was performed by carefully covering slides with the hybridization mixture and sealing them inside $50 \mathrm{~mL}$ Falcon tubes (Corning Inc., Corning, NY USA) as "humidity chambers" containing a moist Kimwipe (Kimberly-Clark, Irving, TX USA) that had been soaked in the hybridization buffer. Hybridization proceeded at $46^{\circ} \mathrm{C}$ for $2 \mathrm{~h}$ before slides were taken out of the humidity chambers and subsequently washed with washing buffer $(60 \mathrm{mM} \mathrm{NaCl}, 20 \mathrm{mM}$ Tris- $\mathrm{HCl}$ at pH 7.4, $5 \mathrm{mM}$ EDTA, $0.01 \% \mathrm{w} / \mathrm{v}$ SDS). Slides were carefully covered with the washing buffer and incubated at $48^{\circ} \mathrm{C}$ for $15 \mathrm{~min}$ inside a $50 \mathrm{~mL}$ Falcon tube containing a moist Kimwipe that had been soaked in the washing buffer. Upon removal, slides were washed twice with distilled MilliQ water, and left to air dry at room temperature before being counterstained with $1 \mathrm{mM}$ 4,6-diaminidino-2-phynylindole (DAPI) following an established protocol [38].

\section{Growth Assessment of FISH-TAMB-Treated Cells}

The fixation-free protocol of FISH-TAMB protocol invites the possibility for cultivating FISH-TAMB-treated cells in the laboratory. To assess the viability of the cells after FISH-TAMB treatment, growth curve analysis was performed on FISH-TAMB-treated cells.

An appropriate volume of E. coli $\mathrm{mcrA}^{+}$, E. coli lacZ ${ }^{+}$, and M. barkeri were diluted to $\sim 10^{6} \mathrm{cells} / \mathrm{mL}$ in 100 $\mathrm{mL}$ of $1 \mathrm{mM}$ mcrA FISH-TAMB (Cy5) probe working solution (equivalent to $100 \mathrm{pmol} \mathrm{MBs}$ ), and hybridization incubation was performed as described above for respective cultures. Subsequently, E. coli cells were inoculated into $2 \mathrm{~mL}$ of aerobic LB/A and M. barkeri into anaerobic DSMZ 120a media. Growth curves were obtained by monitoring $\mathrm{OD}_{600}$ for $E$. coli, and $\mathrm{OD}_{550}$ for $M$. barkeri. A set of reactions without FISH-TAMB probes and of blank media was done in parallel and served as the controls. Optical density was converted to cell concentration (per $\mathrm{mL}$ ) using conversion factor, $8 \times 10^{8}$ cells for one $\mathrm{OD}_{600}$ unit and $1.03 \times 10^{9}$ cells for one $\mathrm{OD}_{550}$ unit. Growth rates $(\mu)$ were determined from the exponential phase of cellular growth plotted on logarithm scale, and were compared between cultures treated with and without FISH-TAMB probes. Doubling time was calculated from the growth rates using this equation: $L N(2) / \mu$. 


\section{Results And Discussion}

\section{FISH-TAMB labels intracellular mRNA targets}

E. coli strains have been used as the workhorse for protein (over)expression because transcription and subsequent translation expression are easily manipulated. Taking advantage of the established system for turning on and off the gene introduced through plasmid transformation, our FISH-TAMB probes can be tested under a controlled gene expression environment.

In the absence of the expression-inducing agent IPTG, flow cytometry showed that a negligible proportion $(0.00 \pm 0.02 \%)$ of uninduced $E$. coli mcrA $^{+}$cells were assigned as FISH-TAMB-labeled (Fig. 2B; Table 1$)$, which was not statistically different from the FISH-TAMB-free controls containing uninduced $E$. coli $\mathrm{mcrA}^{+}(-0.01 \pm 0.03 \%)$ (Fig. $2 \mathrm{~A}$ ) (Student's t-test, $\left.\mathrm{t}=-0.12, \mathrm{p}=0.91\right)$. Barely negative values in Table 1 are due to background subtraction of corresponding events in cell-free blanks, among which one replicate had "FISH-TAMB-labeled cells" detected. Nonetheless, these false positives were within the error of measurement. These two treatments should both be understood as containing $0 \%$ of FISH-TAMB-labeled cells, indicating that the basal expression of the target mcrA gene was generally too low for individual cell detection by FISH-TAMB. By contrast, all $(100.86 \pm 0.56 \%)$ of the induced $E$. coli $\mathrm{mcrA}^{+}$cells were labeled by FISH-TAMB (Fig. 2D), when compared to $0.03 \pm 0.01 \%$ in the parallel samples without FISH-TAMB treatment (Fig. $2 \mathrm{C}$ ), indicating that all cells expressing mcrA expression upon IPTG induction was detectable by the FISH-TAMB method. These results also indicated that the detected Cy 5 signals in the induced $E$. coli $\mathrm{mcrA}^{+}$samples were not attributed to IPTG autofluorescence. In addition, even though $E$. coli JM109 and the PGEM-T Easy vector are a cloning system for DNA propagation, upon induction, the high-copy number of plasmids per cell yielded a sufficiently high mcrA mRNA expression level for FISHTAMB detection.

When the induced E. coli $\mathrm{mcrA}^{+}$cells were treated with lacZa FISH-TAMB probes that target the insertion site, only a very small percentage $(0.01 \% \pm 0.02 \%)$ of cells was assigned as FISH-TAMB-labeled (Fig. 2E). This result indicated that the majority of the mcrA FISH-TAMB-labeled cells did carry an insert that has disrupted the insertion site and it was the mcrA gene insert that resulted in Cy5 fluorescence.

Thanks to flow cytometry that provides a detailed account for gene expression at the single-cell level, these results indicated that FISH-TAMB, when applied at $10^{-3}$ to $10^{-5}$ pmol probes per cell (Table 1 ), detects with high confidence cells that expressed the target mRNA at a considerable level. Further investigation is required to express quantitatively the sensitivity of FISH-TAMB and flow cytometry, such as the minimal copy numbers of the target mRNA per cell for discernable signal-to-background fluorescence.

\section{FISH-TAMB differentiates transcriptional levels}

M. barkeri conserves energy through hydrogenotrophic methanogenesis when grown using $\mathrm{H}_{2}$ as the sole electron donor. As $M$. barkeri cells enter different growth stages due to substrate limitation in batch 
culture, or experience stressful conditions such as exposure to $\mathrm{O}_{2}$, their investment on the energy conservation machinery is anticipated to adjust accordingly, resulting in variation in the expression of mcrA gene. Coupling FISH-TAMB with spinning disk confocal microscopy, we observed significant variability in Cy5 fluorescence level at different growth stages and after $\mathrm{O}_{2}$ exposure (Fig. 3).

During exponential growth phase, the formation of aggregates resulted in only $\sim 28 \%$ of enumerable $M$. barkeri cells (Table 1). All observable cells from the exponential phase detected from F420 autofluorescence were co-labeled with FISH-TAMB probes targeting mcrA mRNA (Fig. 3A). The latter also appeared to be dimmer than the cells from the exponential phase. By comparison, following overnight exposure to atmospheric $\mathrm{O}_{2}$, FISH-TAMB-associated fluorescence appeared only near the center of the aggregate (Fig. 3C), and accounted for fewer than $2 \%$ of all observed cells. Both the decrease in the number of labeled cells and observed drops in Cy5 fluorescence intensity are consistent with anticipated diminished methanogenesis rates typical of prolonged $\mathrm{O}_{2}$ exposure [39]. The spatial pattern of the $m c r A-$ transcribing vs. mcrA-non-transcribing cells also reflected the spatial zonation or heterogeneity of cell aggregates in relationship to nutrient availability and presence of inhibitory substances [40]. The results suggested that the number and fluorescence brightness of cells labeled by FISH-TAMB appear to be affected by the mRNA expression level, although further experiments will be necessary to test this hypothesis and quantitatively evaluate the FISH-TAMB fluorescence and mRNA copy number..

\section{FISH-TAMB detects active, rare taxa}

Time-lapse fluorescence imaging has revolutionized our understanding of cellular activity and compartmentalization [41, 42]. However, real-time tracking of RNA and protein tagged by fluorescent molecules is done, to our best knowledge, on model or engineerable organisms in axenic (co-)cultures. If a similar methodological approach is available for studying uncultured microorganisms, regardless of their abundance (of course, it will be more challenging for the rare taxa), it is foreseen that cellular responses and perhaps physiological and behavioral aspects of uncultured microorganisms can be unveiled. A non-lethal and non-destructive labeling or tagging method would be one of the keys for realizing real-time live-cell imaging of uncultured microorganisms, ideally in environmental samples in the laboratory or even in situ in the field.

AOM activity of the enrichment culture from the borehole BE326 BH2 was confirmed by observation of

${ }^{13} \mathrm{CH}_{4}$ conversion to ${ }^{13} \mathrm{CO}_{2}$. About $3 \%$ of cells were labeled by the mcrA FISH-TAMB probes, which potentially had hybridized to mcrA mRNA in methanogens and ANMEs (Table 1). Metagenomic analysis confirmed the presence of two putatively novel ANME-2 $d$ lineages within the archaeal family Methanoperedenaceae, collectively comprising $1 \%$ relative abundance amongst the Archaea domain and $0.03 \%$ abundance relative to the entire microbial community. Recent evidence suggested that ANME- $2 \mathrm{~d}$ are capable of performing AOM coupled to sulfate reduction [43], though it is not clear whether they are capable of carrying out this process alone or a syntrophic partner is required for electron exchange. Sequences allied to canonical ANME sulfate-reducing bacterial partners Desulfosarcina/Desulfococcus (0.08\%), Desulfobulbus (0.05\%), and Desulfotomaculum (1\%) [44, 45] 
were also detected, though at this time it is unclear if any of these groups partners metabolically with the identified ANME-2d lineages.

Using spinning-disk fluorescence confocal microscopy, we monitored the FISH-TAMB-labeled cells from the AOM enrichment. Various cell morphologies were observed over the first 4 hours of monitoring, snapshots at $0,20,120$, and 240 mins were taken for single planktonic cells (Fig. 4A), paired cells (Fig. 4B and 4C), and cell aggregates (Fig. 4D). Interestingly, a cell duplet appeared to have undergone some changes over the course of observation, wherein a second labeled cell seemed to emerge from the original one of larger size (Fig. 4B and Video S2). Because of the short response time of the PFS of the microscope, it is unlikely that focus drift artificially generated the fluorescence signal by bringing an outof-focus cell into view. The emergence of second labeled cell could therefore be explained by several scenarios: 1) rotation of two labeled cells about the focal plane, bringing an out-of-sight cell into view; 2) ongoing cell division during imaging, during which time the cells rotated about the focal plane, revealing a daughter cell with labeled mcrA mRNA adopted in the cytoplasm. Doubling times of sulfate-dependent AOM have been observed between 1.1 and 7.5 months [46], and as our AOM enrichment was incubated for 50 days, it would not be unexpected to observe dividing cells; or 3) the Cy5 fluorescence level in the second cell was initially below detection, and later it attained a detectable range. This curious finding warrants further experimentation to visually document the FISH-TAMB hybridization process to see how FISH-TAMB may be used for real-time labeling of newly formed target mRNA in the cytoplasm.

To establish the efficacy of FISH-TAMB as a method for tracking transcriptional activity of uncultivated lineages, AOM enrichment samples freshly treated with mcrA FISH-TAMB probes were subjected to the traditional (fixation required) 16S rRNA FISH protocol to identify ANME-2 archaea. Cells labeled by the mcrA FISH-TAMB probes were also labeled by the EelMS-932 probe, confirming that the mcrA FISH-TAMBlabeled cells include ANME-2, an active minority group. The ANME-2 cells were situated in consortia with DAPI-only labeled cells (Fig. 5), which were potentially the syntrophic partner sulfate-reducing bacteria (SRB) $[8,23]$ identified in the metagenome. These results provided the first microscopic evidence of active AOM-performing microbial consortia from the continental deep biosphere.

\section{FISH-TAMB shows little impact to cell viability}

To illustrate if FISH-TAMB treated cells remained culturable, we monitored the growth of E. coli mcrA ${ }^{+}, E$. coli lacZ ${ }^{+}$, and $M$. barkeri incubated with and without FISH-TAMB probes. All cultures treated with FISHTAMB probes showed a similar duration of lag and exponential phases and entered the stationary phase at a similar time (Fig. 6). Both FISH-TAMB-treated and untreated $E$. coli exhibited similar growth rates (Fig. 6A). The specific growth rates of $E$. coli $\mathrm{mcrA}^{+}$treated with or without $\mathrm{mcrA}$ FISH-TAMB probes were not significantly different from each other (Student's $t$-test, $t=0.495, p=0.65$ ), with $\mu_{\text {FISH-TAMB }}=1.07 \pm 0.17$ $\mathrm{h}^{-1}$ and $\mu_{\text {control }}=1.14 \pm 0.13 \mathrm{~h}^{-1}$, respectively. The specific growth rates of $E$. coli lacZ ${ }^{+}$treated with or without lacZ FISH-TAMB probes were also not significantly different from each other (Student's t-test, $\mathrm{t}=0.153, \mathrm{p}=0.89$ ), with $\mu_{\mathrm{FISH}-\mathrm{TAMB}}=0.99 \pm 0.19 \mathrm{~h}^{-1}$ and $\mu_{\text {control }}=1.01 \pm 0.08 \mathrm{~h}^{-1}$, respectively. The corresponding doubling times ranged from 0.55 to $0.91 \mathrm{~h}$. The specific growth rates for both control 
$\left(\mu_{\text {control }}\right)$ and FISH-TAMB-treated $\left(\mu_{\text {FISH-TAMB }}\right)$ M. barkeri were $0.04 \pm 0.00 \mathrm{~h}^{-1}$ (Fig. $\left.6 \mathrm{~B}\right)$, which are consistent with previously reported values for hydrogenotrophic $M$. barkeri growth [47]. The corresponding doubling times ranged from 14.31 to $17.70 \mathrm{~h}$. These results showed that the applied FISHTAMB dosage $\left(10^{-3}\right.$ to $10^{-5}$ pmol MBs per cell as in Table 1$)$ had no observable inhibitory effect on the growth of these pure cultures.

\section{Implications of FISH-TAMB for Microbial Ecology}

FISH-TAMB utilizes polyarginine CPP to deliver MBs across prokaryotic cell walls and membranes, fluorescently labeling cells when MBs hybridize to target mRNA sequences. Hybridization occurs in isotonic buffer containing no fixatives or strong surfactants, at the (optimal) growth temperature of the tested cultures and enrichments, and in as short as 15 mins. We demonstrated that FISH-TAMB labels intracellular mRNA targets, differentiates transcriptional states, detects active and rare taxa, and keeps cell viability. Coupling FISH-TAMB with various fluorescence detection approaches would enable qualitative and/or (semi-) quantitative studies of the target mRNA and its host cells, as well as physically associated cells exhibiting parasitic or syntrophic relationship. Although FISH-TAMB was initially envisioned for mRNA of any functional gene of interest without a requirement of prior knowledge of $16 \mathrm{~S}$ rRNA-based taxonomy, FISH-TAMB has the potential for going beyond mRNA and multiplexing. Thus, FISH-TAMB is a versatile addition to the molecular ecologist's toolkit, with potential widespread application in the field of environmental microbiology.

While FISH-TAMB provides the first step towards identifying rare, uncultured taxa as active players or keystone species in the deep biosphere and other ecosystems, continued development of FISH-TAMB is necessary to understand the limits of its application in other systems (e.g. temperature, salinity, and pH extremes; sensitivity to spore forming, gram-positive bacteria; double-membraned archaea [48]; the detection limit for transcript copy numbers; optimal, toxic and lethal dosages respective to microbial lineages, etc.). Then, FISH-TAMB can truly enable us to characterize the genomes and physiologies of the labeled cells, and subsequently to evaluate or perhaps even quantify their ecological importance.

\section{Declarations}

The authors have no conflicts of interest to declare that are relevant to the content of this article.

Author Contributions: M.C.Y.L. invented the concept of FISH-TAMB. R.L.H, M.C.Y.L., and T.C.O. contributed to experimental design. R.L.H., M.C.Y.L, and A.T. performed in vitro hybridization assays. R.L.H., M.C.Y.L, and A.T. were responsible for the maintenance of $E$. coli clone lines. R.L.H. maintained M. barkeri and BE326 BH2-PC enrichment cultures. R.L.H. performed in vivo hybridization assays, microscopy, and flow cytometry. C.J.D. assisted R.L.H. in the acquisition of flow cytometry data. G.L. assisted R.L.H. in microscopy. R.L.H., M.C.Y.L., T.C.O., T.L.K., E van H., E.C., and J.V. collected environmental samples from the $\mathrm{BE} 326 \mathrm{BH} 2$ borehole. All authors contributed in the preparation of this manuscript. 
Acknowledgements: We are indebted to Sibanye Gold, Ltd. and the staff at the Beatrix Gold Mine for their hospitality and granting us continued access to the BE326 BH2 borehole. We would like to thank Mike Pullin, Gilbert Tetteh, Sarah Hendrickson and Olukayode Kuloyo for their field assistance. Special thanks are extended to Rick Colwell, Hillary Morrison, and the Marine Biological Laboratory for supporting sequencing efforts through the Deep Carbon Observatory's Census of Deep Life. M.C.Y.L. and R.L.H. would like to thank Ewa Zarnowska and Tao Liang of Bruker Scientific Instruments (Florescence Microscopy) for imaging FISH-TAMB labeled E. coli at their facility in Middleton, WI. R.L.H. is thankful to Douglas $\mathrm{H}$. Bartlett and his lab for hosting her visiting research supported through the Deep Carbon Observatory Deep Life Cultivation Internship (Alfred P. Sloan Foundation).

This project was supported by funding from National Science Foundation grants DGE-1148900 to R.L.H. and DEB-1441717, EAR-1528492, DEB-1442059, and DEB-1441646 grants awarded to T.C.O. R.L.H. was also supported by the Geosciences Graduate Student Research Fund (Princeton University). Metagenomic sequencing was supported by Phase 14 of the Census of Deep Life (Deep Carbon Observatory, Alfred P. Sloan Foundation). Pioneer work was supported by funding from the Department of Geosciences, Princeton University to A.T. The Princeton University Flow Cytometry Resource Facility is supported, in part, with funding from NCI-CCSG P30CA072720-5921. Any opinions, findings, and conclusions or recommendations expressed in this material are those of the authors and do not necessarily reflect the views of the National Science Foundation.

Raw sequencing data from the $\mathrm{BE} 326 \mathrm{BH} 2-\mathrm{Conc} \mathrm{AOM}$ enrichment metagenome have been deposited at NCBI GenBank under accession number PRJNA562560 (Sequence Read Archive accession number SRR10029121).

\section{References}

1. Banerjee S, Schlaeppi K, van der Heijden MGA (2018) Keystone taxa as drivers of microbiome structure and functioning. Nat Rev Microbiol 16:567-576. https://doi.org/10.1038/s41579-018-0024-1

2. Cottee-Jones HEW, Whittaker RJ (2012) perspective: The keystone species concept: a critical appraisal. Front Biogeogr 4:. https://doi.org/10.21425/f5fbg12533

3. Kietäväinen R, Purkamo L (2015) The origin, source, and cycling of methane in deep crystalline rock biosphere. Front Microbiol 6:725. https://doi.org/10.3389/fmicb.2015.00725

4. Chivian D, Brodie EL, Alm EJ, et al (2008) Environmental genomics reveals a single-species ecosystem deep within Earth. Science 322:275-278. https://doi.org/10.1126/science.1155495

5. Onstott TC (2017) Deep Life: The Hunt for the Hidden Biology of Earth, Mars, and Beyond. Princeton University Press, Princeton 
6. Sogin ML, Morrison HG, Huber JA, et al (2006) Microbial diversity in the deep sea and the underexplored "rare biosphere." Proc Natl Acad Sci USA 103:12115-12120.

https://doi.org/10.1002/9781118010549.ch24

7. Rinke C, Schwientek P, Sczyrba A, et al (2013) Insights into the phylogeny and coding potential of microbial dark matter. Nature 499:431-437. https://doi.org/10.1038/nature12352

8. Lau MCY, Kieft TL, Kuloyo O, et al (2016) An oligotrophic deep-subsurface community dependent on syntrophy is dominated by sulfur-driven autotrophic denitrifiers. Proc Natl Acad Sci U S A 113:E7927E7936. https://doi.org/10.1073/pnas.1612244113

9. DeLong EF, Wickham GS, Pace NR (1989) Phylogenetic stains: Ribosomal RNA-based probes for the identification of single cells. Science 243:1360-1362

10. Pernthaler A, Amann R (2004) Simultaneous fluorescence in situ hybridization of mRNA and rRNA in environmental bacteria. Appl Environ Microbiol 70:5426-5433.

https://doi.org/10.1128/AEM.70.9.5426

11. Sokol DL, Zhang X, Lu P, Gewirtz AM (1998) Real time detection of DNA-RNA hybridization in living cells. Proc Natl Acad Sci USA 95:11538-11543

12. Braissant O, Wahli W (1998) A simplified in situ hybridization protocol using non-radioactively labeled probes to detect abundant and rare mRNAs on tissue sections. Biochemica 1:10-16

13. Choi HMT, Beck VA, Pierce NA (2014) Next-generation in situ hybridization chain reaction: Higher gain, lower cost, greater durability. ACS Nano 8:4284-4294. https://doi.org/10.1021/nn405717p

14. Wile BM, Ban K, Yoon YS, Bao G (2014) Molecular beacon-enabled purification of living cells by targeting cell type-specific mRNAs. Nat Protoc 9:2411-2424. https://doi.org/10.1038/nprot.2014.154

15. Hatzenpichler R, Scheller S, Tavormina PL, et al (2014) In situ visualization of newly synthesized proteins in environmental microbes using amino acid tagging and click chemistry. Environ Microbiol 16:2568-2590. https://doi.org/10.1111/1462-2920.12436

16. Hoffman EA, Frey BL, Smith LM, Auble DT (2015) Formaldehyde crosslinking: A tool for the study of chromatin complexes. J Biol Chem 290:26404-26411. https://doi.org/10.1074/jbc.R115.651679

17. Yilmaz S, Haroon MF, Rabkin BA, et al (2010) Fixation-free fluorescence in situ hybridization for targeted enrichment of microbial populations. ISME J 4:1352-1356.

https://doi.org/10.1038/ismej.2010.73

18. Pernthaler J, Glöckner F-O, Schönhuber W, Amann R (2001) Fluorescence in situ hybridization (FISH) with rRNA-targeted oligonucleotide probes. In: Methods in Microbiology Vol. 30. pp 207-226 
19. Haroon MF, Skennerton CT, Steen JA, et al (2013) In-solution fluorescence in situ hybridization and fluorescence-activated cell sorting for single cell and population genome recovery, 1 st ed. Elsevier Inc.

20. Batani G, Bayer K, Böge J, et al (2019) Fluorescence in situ hybridization (FISH) and cell sorting of living bacteria. Sci Rep 9:18618. https://doi.org/10.1038/s41598-019-55049-2

21. Hallam SJ, Girguis PR, Preston CM, et al (2003) Identification of methyl coenzyme M reductase A genes associated with methane-oxidizing archaea. Appl Environ Microbiol 69:5483-5491. https://doi.org/10.1128/AEM.69.9.5483

22. Simkus DN, Slater GF, Sherwood Lollar B, et al (2016) Variations in microbial carbon sources and cycling in the deep continental subsurface. Geochim Cosmochim Acta 173:264-283. https://doi.org/10.1016/j.gca.2015.10.003

23. Magnabosco C, Timmers PHA, Lau MCY, et al (2018) The case for a dynamical subsurface ecosystem. FEMS Microbiol Ecol accepted: https://doi.org/http://dx.doi.org/10.1101/040204

24. Tyagi S, Kramer FR (1996) Molecular beacons: Probes that fluoresce upon hybridization. Nat Biotechnol 14:303-308. https://doi.org/10.1038/nbt0396-303

25. Bao G, Rhee WJ, Tsourkas A (2009) Fluorescent probes for live-cell RNA detection. Annu Rev Biomed Eng 11:25-47. https://doi.org/10.1146/annurev-bioeng-061008-124920.Fluorescent

26. Larsson HM, Lee ST, Roccio M, et al (2012) Sorting live stem cells based on Sox2 mRNA expression. PLoS One 7:e49874. https://doi.org/10.1371/journal.pone.0049874

27. Liu BR, Huang Y-W, Lee H-J (2013) Mechanistic studies of intracellular delivery of proteins by cellpenetrating peptides in cyanobacteria. BMC Microbiol 13:57. https://doi.org/10.1186/1471-2180-13-57

28. Liu BR, Liou JS, Huang YW, et al (2013) Intracellular delivery of nanoparticles and DNAs by IR9 cellpenetrating peptides. PLoS One 8:37-41. https://doi.org/10.1371/journal.pone.0064205

29. Liu BR, Huang YW, Aronstam RS, Lee HJ (2015) Comparative mechanisms of protein transduction mediated by cell-penetrating peptides in prokaryotes. J Membr Biol 248:355-368. https://doi.org/10.1007/s00232-015-9777-x

30. Steinberg LM, Regan JM (2008) Phylogenetic comparison of the methanogenic communities from an acidic, oligotrophic fen and an anaerobic digester treating municipal wastewater sludge. Appl Environ Microbiol 74:6663-6671. https://doi.org/10.1128/AEM.00553-08

31. Yilmaz LS, Parnerkar S, Noguera DR (2011) MathFISH, a web tool that uses thermodynamicsbased mathematical models for in silico evaluation of oligonucleotide probes for fluorescence in situ hybridization. Appl Environ Microbiol 77:1118-1122. https://doi.org/10.1128/AEM.01733-10 
32. Peng L, Tan W (2013) Thermodynamic and kinetic properties of molecular beacons. In: Yang CJ, Tan W (eds) Molecular Beacons. Springer Berlin Heidelberg, Berlin, Heidelberg, pp 19-43

33. Anderson KL, Apolinario EE, Sowers KR (2012) Desiccation as a long-term survival mechanism for the archaeon Methanosarcina barkeri. Appl Environ Microbiol 78:1473-1479. https://doi.org/10.1128/AEM.06964-11

34. Luesken FA, Zhu B, Van Alen TA, et al (2011) pmoA Primers for detection of anaerobic methanotrophs. Appl Environ Microbiol 77:3877-3880. https://doi.org/10.1128/AEM.02960-10

35. Renggli S, Keck W, Jenal U, Ritz D (2013) Role of autofluorescence in flow cytometric analysis of Escherichia coli treated with bactericidal antibiotics. J Bacteriol 195:4067-4073. https://doi.org/10.1128/JB.00393-13

36. Boetius A, Ravenschlag K, Schubert CJ, et al (2000) A marine microbial consortium apparently mediating anaerobic oxidation methane. Nature 407:623-626. https://doi.org/10.1038/35036572

37. Hatzenpichler R, Connon SA, Goudeau D, et al (2016) Visualizing in situ translational activity for identifying and sorting slow-growing archaeal-bacterial consortia. Proc Natl Acad Sci 113:E4069-E4078. https://doi.org/10.1073/pnas.1603757113

38. Glöckner FO, Amann R, Alfreider A, et al (1996) An in situ hybridization protocol for detection and identification of planktonic bacteria. Syst Appl Microbiol 19:403-406. https://doi.org/10.1016/S07232020(96)80069-5

39. Fetzer S, Bak F, Conrad R (1993) Sensitivity of methanogenic bacteria from paddy soil to oxygen and desiccation. FEMS Microbiol Ecol 12:107-115. https://doi.org/10.1111/j.1574-6941.1993.tb00022.x

40. Paerl HW, Pinckney JL (1996) A mini-review of microbial consortia: Their roles in aquatic production and biogeochemical cycling. Microb Ecol 31:225-247.

https://doi.org/10.1017/CB09781107415324.004

41. Golding I, Paulsson J, Zawilski SM, Cox EC (2005) Real-time kinetics of gene activity in individual bacteria. Cell 123:1025-1036. https://doi.org/10.1016/j.cell.2005.09.031

42. Buskila A-AA, Kannaiah S, Amster-Choder O (2014) RNA localization in bacteria. RNA Biol 11:1051-1060. https://doi.org/10.4161/rna.36135

43. Weber HS, Habicht KS, Thamdrup B (2017) Anaerobic methanotrophic archaea of the ANME-2d cluster are active in a low-sulfate, iron-rich freshwater sediment. Front Microbiol 8:619. https://doi.org/10.3389/fmicb.2017.00619

44. Knittel K, Boetius A (2009) Anaerobic oxidation of methane: progress with an unknown process. Annu Rev Microbiol 63:311-334. https://doi.org/10.1146/annurev.micro.61.080706.093130 
45. Li L, Xue S, Xi J (2019) Anaerobic oxidation of methane coupled to sulfate reduction: Consortium characteristics and application in co-removal of H2S and methane. J Environ Sci 76:238-248. https://doi.org/10.1016/j.jes.2018.05.006

46. Timmers PHA, Welte CU, Koehorst JJ, et al (2017) Reverse Methanogenesis and Respiration in Methanotrophic Archaea. Archaea 2017:1654237. https://doi.org/10.1155/2017/1654237

47. Maestrojuan GM, Boone DR (1991) Characterization of Methanosarcina barkeri MST and 227, Methanosarcina mazei S-6T, and Methanosarcina vacuolata Z-761T. Int J Syst Bacteriol 41:267-274

48. Rachel R, Wyschkony I, Riehl S, Huber H (2002) The ultrastructure of Ignicoccus: Evidence for a novel outer membrane and for intracellular vesicle budding in an archaeon. Archaea 1:9-18. https://doi.org/10.1155/2002/307480

\section{Table}

Table 1 is available in the Supplementary Files.

\section{Figures}




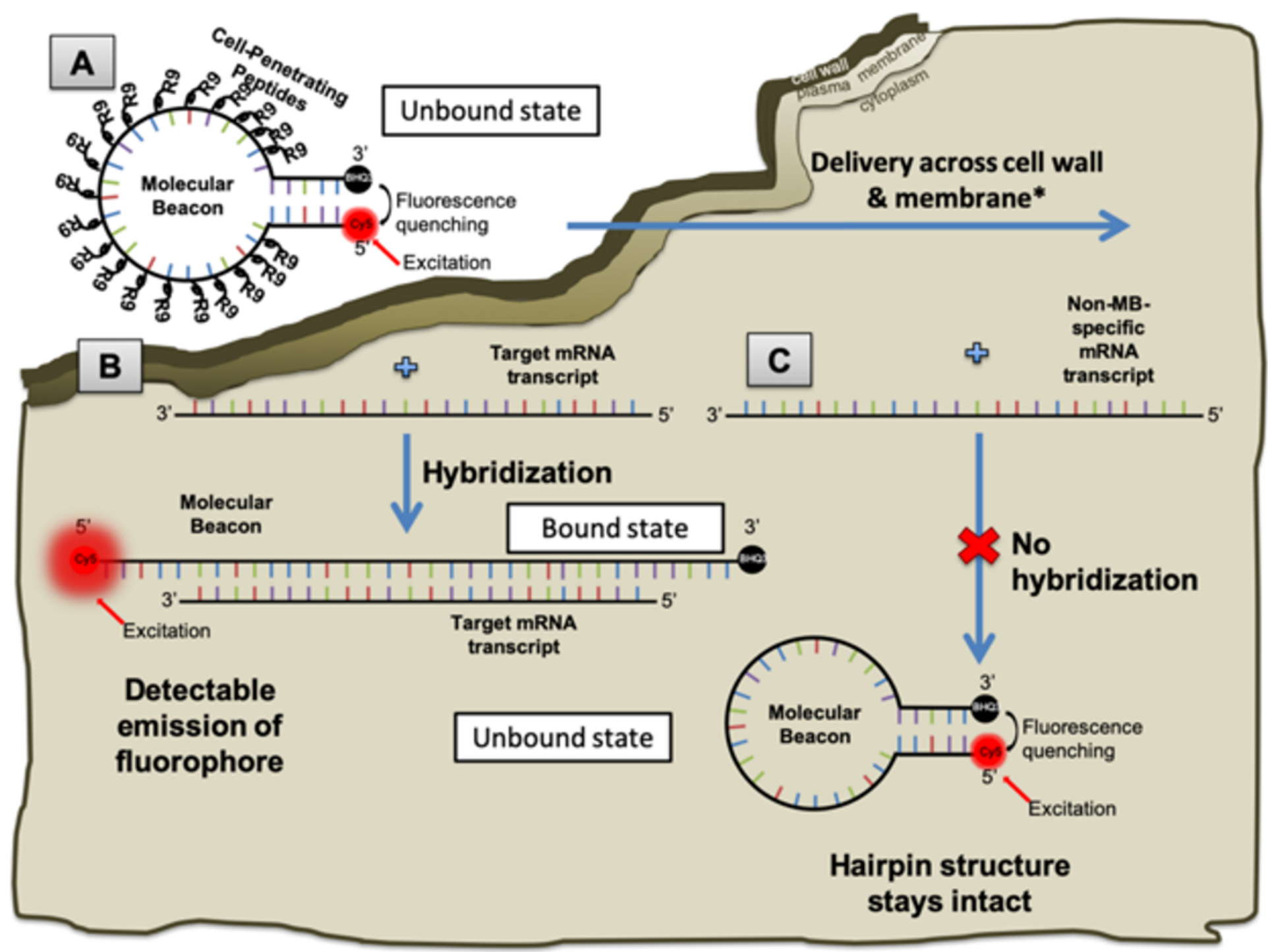

Figure 1

FISH-TAMB probe conformation and hybridization to encountered messenger RNAs. (A) An oligomer comprised of a 24 base-long complementary mcrA mRNA sequence is flanked by 5 reverse complement nucleotides to form a molecular beacon (MB) loop and stem structure. Cell-penetrating peptides (CPPs) comprising 9 arginine sequences (R9) are non-covalently bound to the MB sequence and are responsible for its delivery across the cell wall and plasma membrane. (B) Fluorescence of Cy5 fluorophore covalently bound to the $5^{\prime}$ end of the MB sequence remains quenched by BHQ3 bound to the $3^{\prime}$ terminus until the $M B$ hybridizes to a target transcript sequence. Hybridization results in the linearization of the MB, subsequently unquenching Cy 5 from BHQ3, allowing the fluorophore's emission upon excitation by a source in the red bandwidth of the visible light spectrum. (C) If the MB encounters an mRNA transcript that is not its intended target, it will retain its hairpin conformation and fluorescence of Cy5 will remain quenched by BHQ3. Images not to scale. 

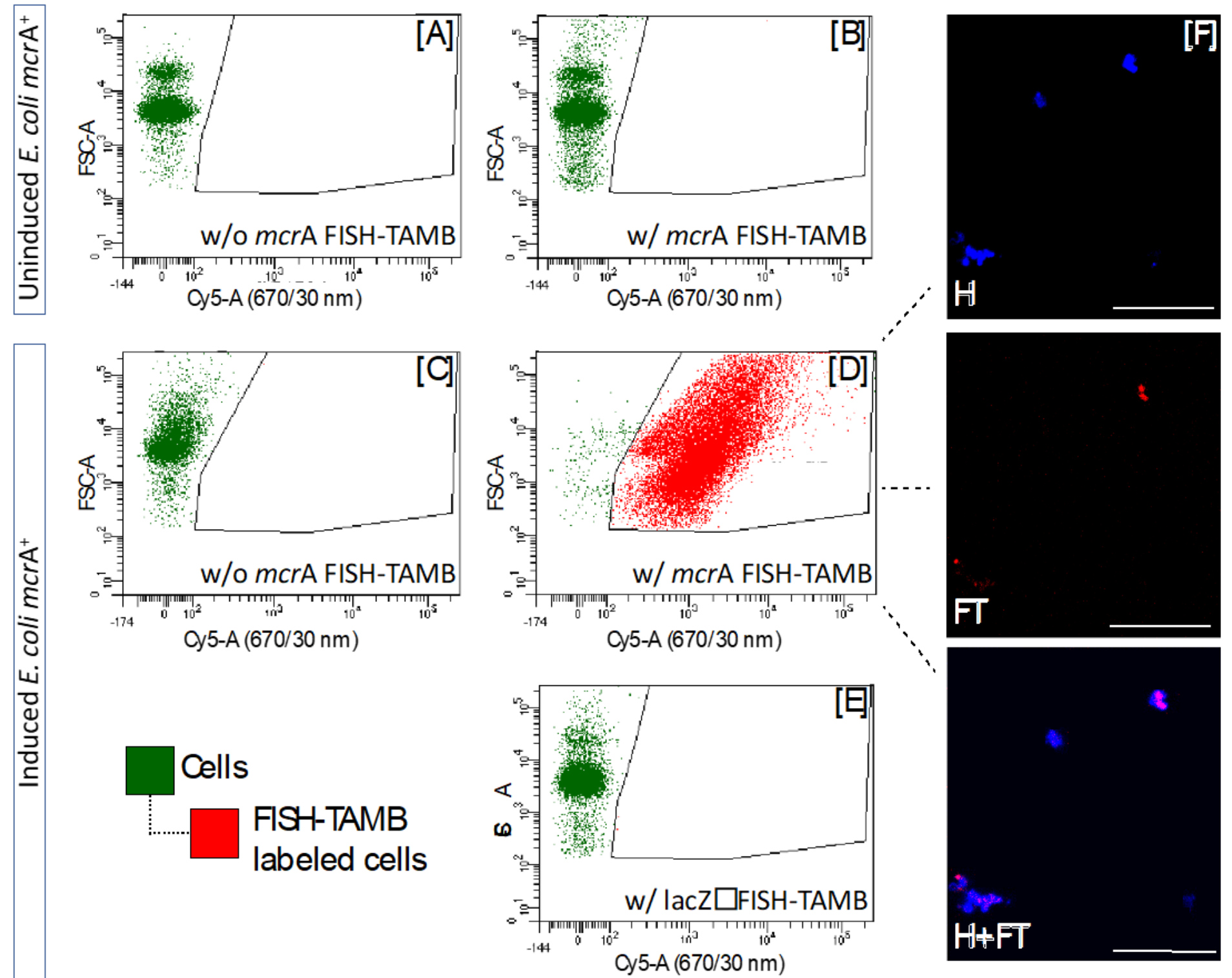

\section{Figure 2}

Flow cytometry data of FISH-TAMB targeting messenger RNA in E. coli grown in the absence (uninduced) or presence (induced) of IPTG, which triggers the transcription of the lac operon containing this gene. Events with optical properties similar to as E. coli cells are gated in green as cells. FISH-TAMB targeting mcrA in induced E. coli mcrAt is indicated by the population gated in red. Cy 5 was excited at $640 \mathrm{~nm}$ and emitted fluorescence collected via $670 / 30 \mathrm{~nm}$ bandpass filter. (A) Uninduced E. coli mcrA+ without FISHTAMB treatment. (B) Uninduced E. coli mcrA+ treated with FISH-TAMB probes targeting mcrA mRNA. (C) IPTG-induced E. coli mcrA+ without FISH-TAMB treatment. (D] IPTG-induced E. coli mcrA+ treated with FISH-TAMB probes targeting mcrA mRNA. (E) IPTG-induced E. coli mcrA+ treated with FISH-TAMB probes targeting lacZa mRNA (F) Fluorescence microscopy of IPTG-induced E. coli mcrA+ treated with FISHTAMB probes targeting mcrA mRNA. $\mathrm{H}$, Hoechst-33342; FT, Cy5 fluorescence from FISH-TAMB labeling; $\mathrm{H}+\mathrm{FT}$, composite of $\mathrm{H}$ and FT micrographs. Scale bar $10 \mu \mathrm{m}$. 

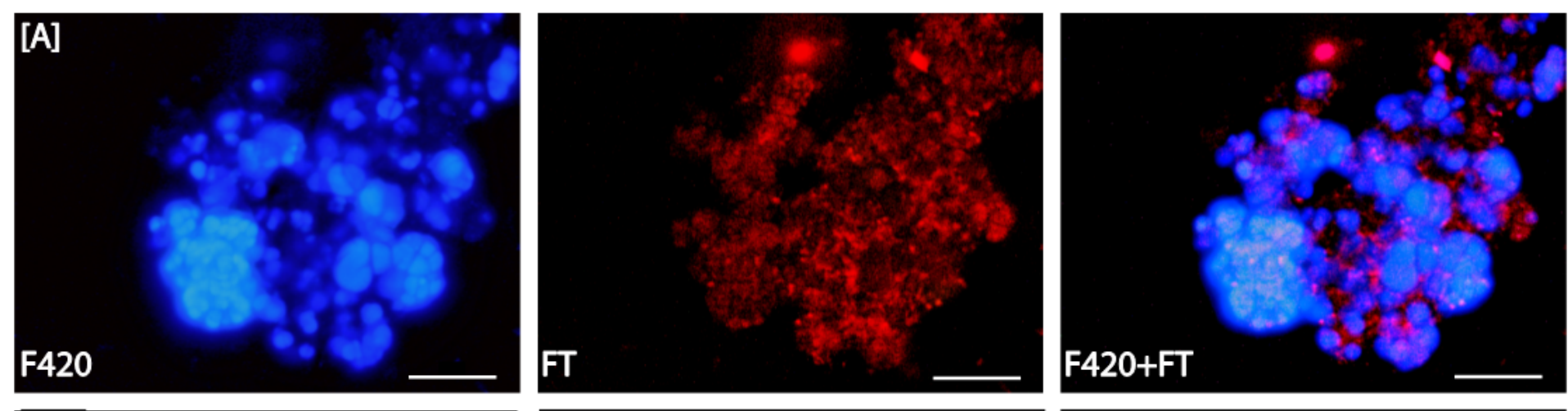

\section{[B]}
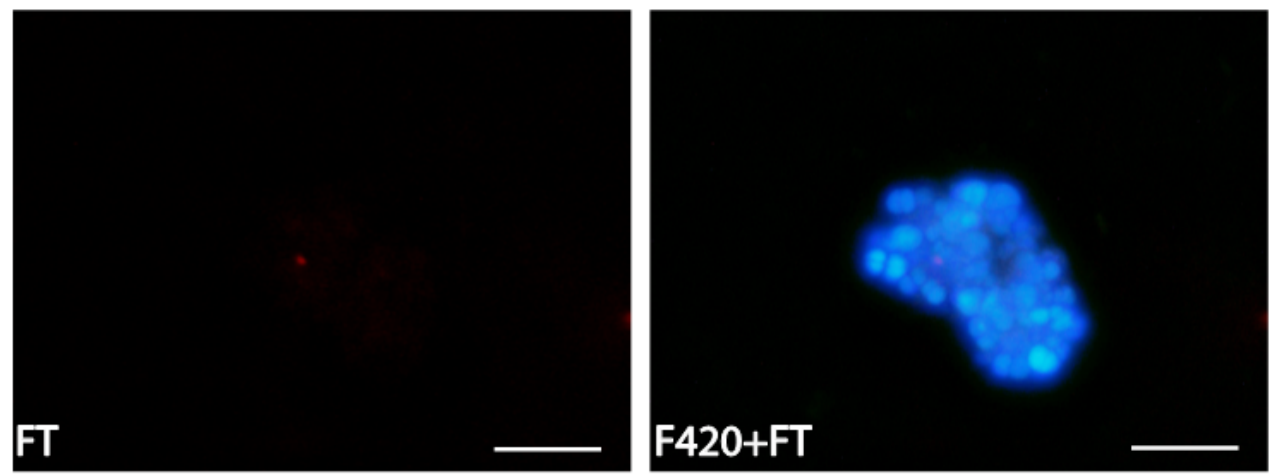

\section{Figure 3}

FISH-TAMB sensitivity to mcrA transcription in Methanosarcina barkeri during (A) exponential phase, and (B) following overnight exposure to air. F420, F420 autofluorescence; FT, Cy5 fluorescence from FISHTAMB labeling; F420+FT, composite image of F420 and FT micrographs. Scale bar $10 \mu \mathrm{m}$. 


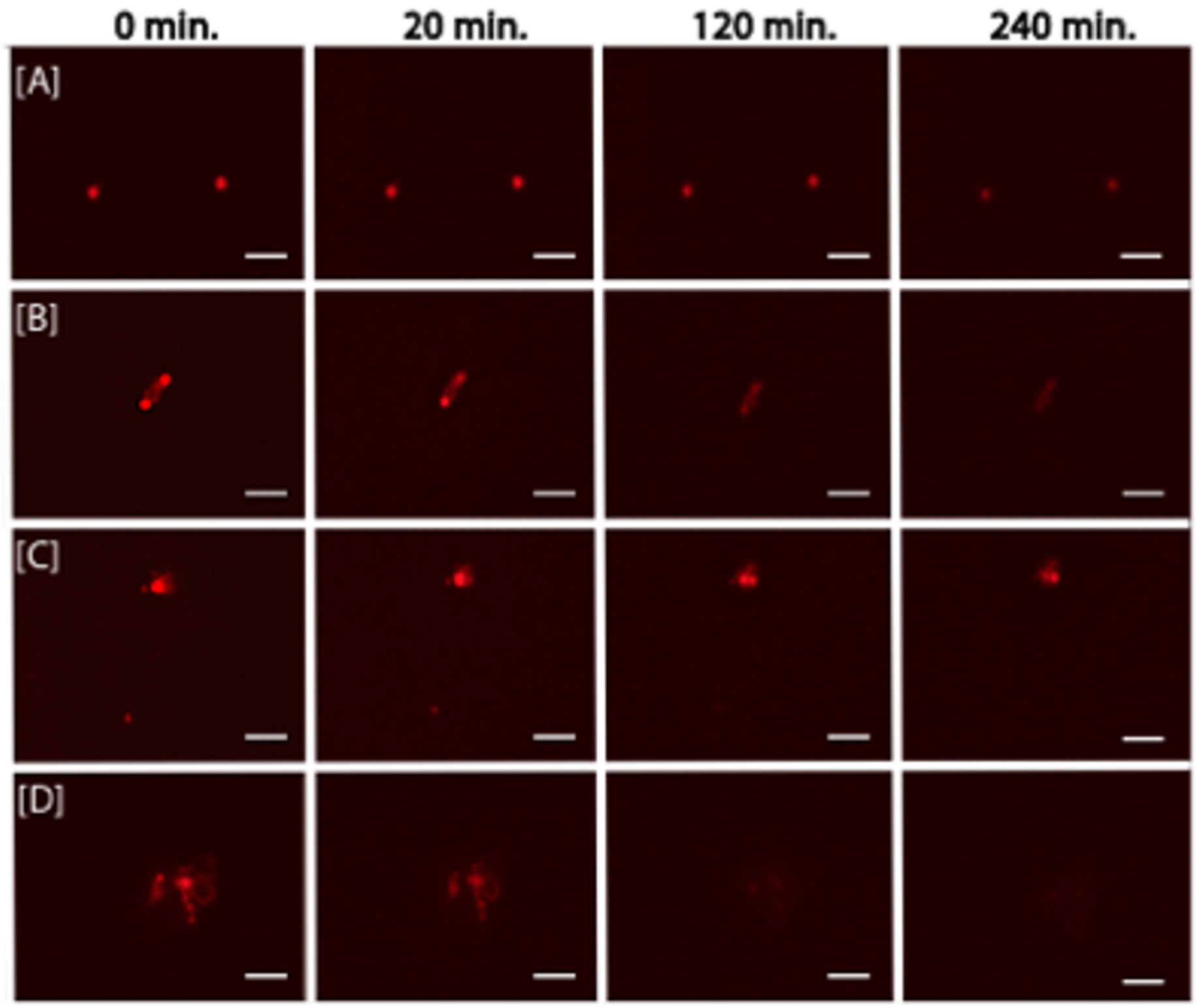

Figure 4

Cell morphologies of ANME enrichment culture labeled by mcrA FISH-TAMB probes. (A) Single cells; (B) and (C) Physically associated cells; and (D) Cell aggregate. Micrographs were snapped every minute for 14 hours. Micrographs here represent the first four hours of observation. Scale bar $5 \mu \mathrm{m}$. 

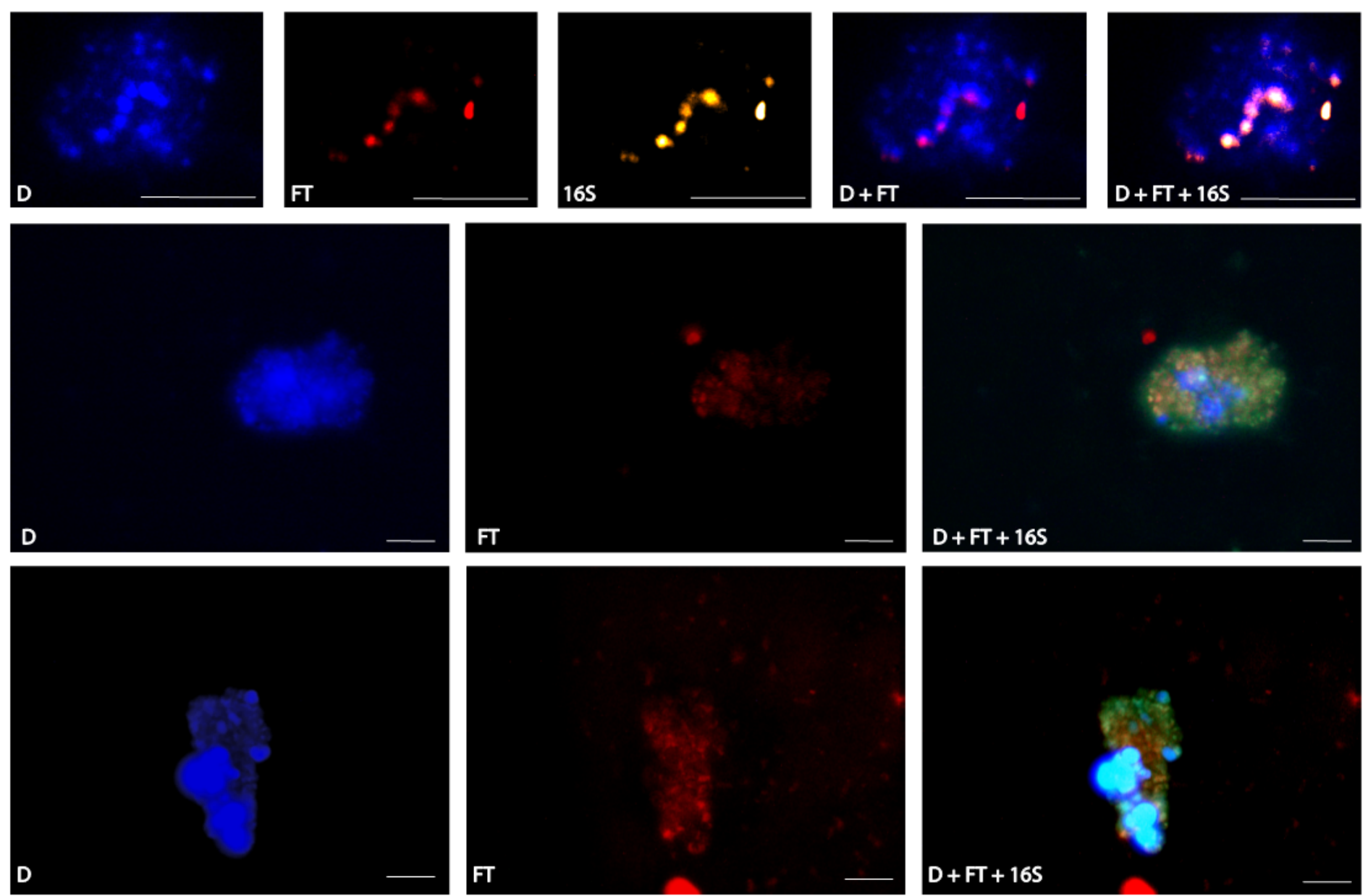

\section{Figure 5}

Co-labeling of active ANME-2 cells in ANME enrichment cultures by FISH-TAMB and 16S rRNA FISH. D, DAPI; FT, Cy 5 fluorescence from FISH-TAMB labeling, 16S, Atto 565 fluorescence from 16S rRNA FISH labeling; D+FT+16S, composite of D, FT, and 16S micrographs. Scale bar $10 \mu \mathrm{m}$. 


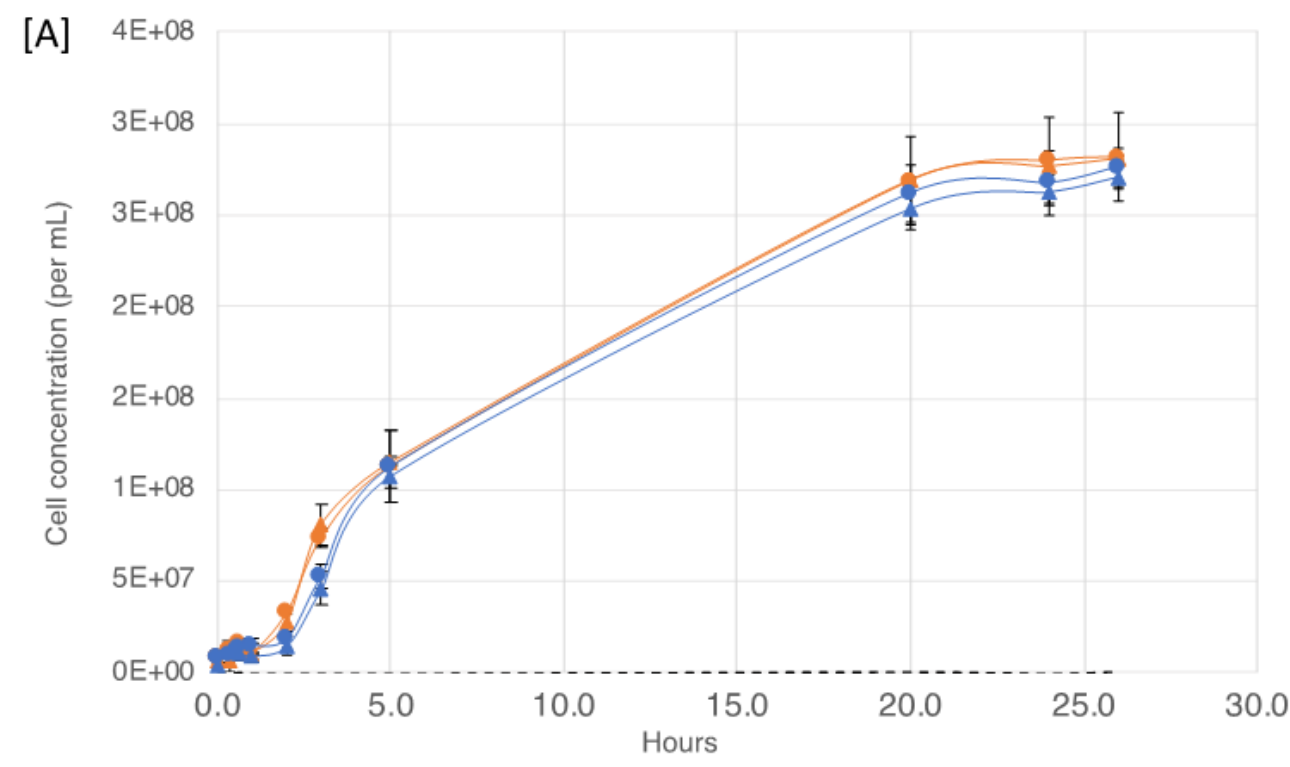

\section{Treatment}

- FISH-TAMB treatment

$\Delta$ No treatment

\section{Cell culture}

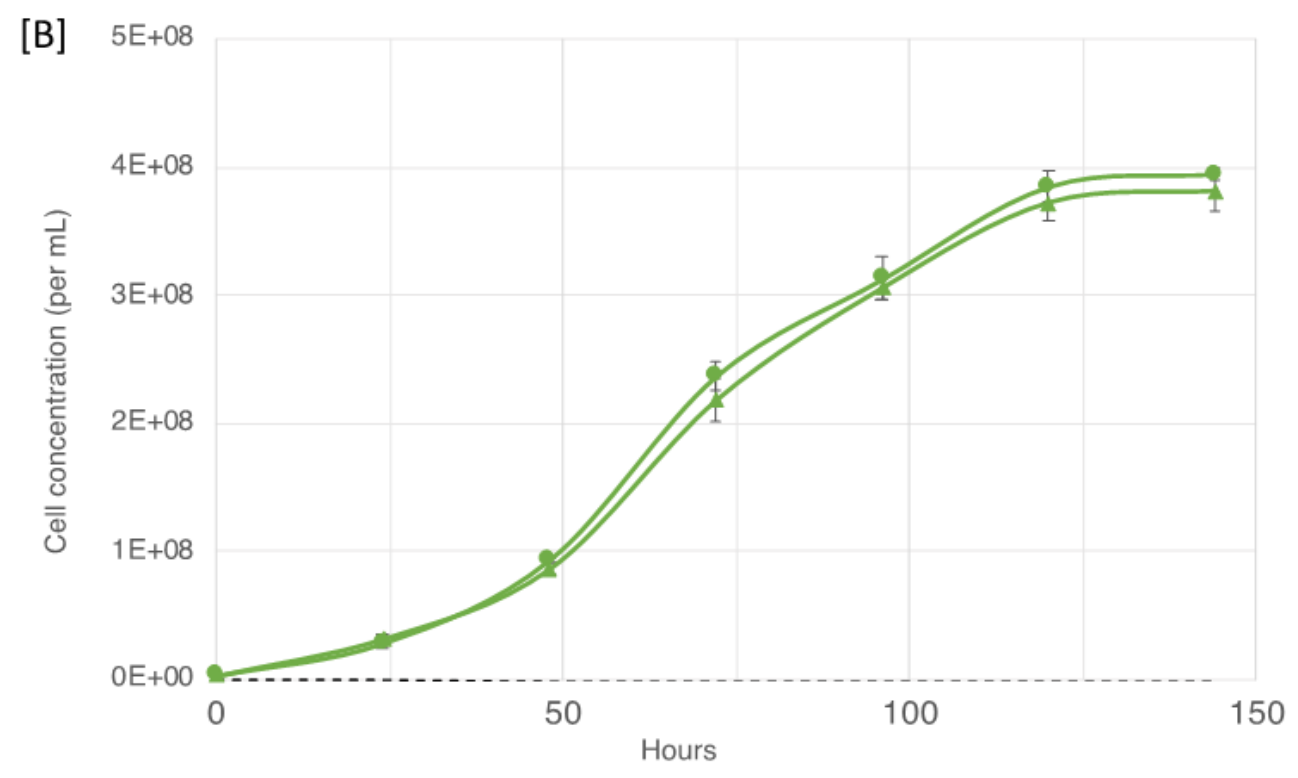

\section{Figure 6}

FISH-TAMB viability assessment by growth curve analysis. Pure cultures of (A) E. coli mcrAt and E. coli lacZa+ and (B) M. barkeri ( 106 cells ml-1) were incubated with $1 \mu \mathrm{M}$ FISH-TAMB probes and inoculated into their respective growth media.

\section{Supplementary Files}

This is a list of supplementary files associated with this preprint. Click to download.

- Table.docx

- HarrisetalFISHTAMBMicroEcolsuppwCompFigsrebonline.docx

- VideoS1Ecoli3D.avi

- VideoS2bBE326Hfluorescencepng10fps.avi 